\title{
Synthesis of ZnO Nanoparticles to Fabricate a Mask-Free Thin-Film Transistor by Inkjet Printing
}

\author{
Chao-Te Liu, Wen-Hsi Lee, and Tsu-Lang Shih \\ Department of Electrical Engineering, National Cheng Kung University, Tainan City 701, Taiwan \\ Correspondence should be addressed to Wen-Hsi Lee, leewen@mail.ncku.edu.tw
}

Received 30 April 2011; Accepted 31 May 2011

Academic Editor: Guozhen Shen

Copyright () 2012 Chao-Te Liu et al. This is an open access article distributed under the Creative Commons Attribution License, which permits unrestricted use, distribution, and reproduction in any medium, provided the original work is properly cited.

\begin{abstract}
We report a low-cost, mask-free, reduced material wastage, deposited technology using transparent, directly printable, air-stable semiconductor slurries and dielectric solutions. We have demonstrate an emerging process for fabricating printable transistors with $\mathrm{ZnO}$ nanoparticles as the active channel and poly(4-vinylphenol) (PVP) matrix as the gate dielectric, respectively, and the inkjetprinted ZnO TFTs have shown to exhibit the carrier mobility of $0.69 \mathrm{~cm}^{2} / \mathrm{Vs}$ and the threshold voltage of $25.5 \mathrm{~V}$. We suggest that the printable materials and the printing technology enable the use of all-printed low-cost flexible displays and other transparent electronic applications.
\end{abstract}

\section{Introduction}

Solution-processable organic semiconductors such as pentacene, poly(3-hexylthiophene) (P3HT), and $\alpha, \omega$-dihexylquaterthiophene (DH4T) have been also investigated, but they exhibits low mobility $\left(<0.1 \mathrm{~cm}^{2} / \mathrm{Vs}\right)$ and poor stability against humidity [1-3] in common processes. For these reasons, solution-processed inorganic materials that are stable in air and suitable for solution processes have attracted recent research interest.

Metal oxides are well-known high carrier mobility, and transparent conducting materials as $\mathrm{SnO}_{2}, \mathrm{In}_{2} \mathrm{O}_{3}, \mathrm{ZnO}$ [4], and other mixed oxide of $\mathrm{Ga}$, In or $\mathrm{Sn}$, and $\mathrm{Zn}$ as amorphous semiconductors, such as IGO, ZTO, IZO, and IGZO [5-9]. They usually reveal n-type property by virtue of oxygen vacancies or incorporation and also can achieve high mobility of $1-100 \mathrm{~cm}^{2} / \mathrm{Vs}$ in amorphous state $[5,10]$, much higher than a-Si $\left(\leqq 1 \mathrm{~cm}^{2} / \mathrm{Vs}\right)$. These materials can be deposited by vacuum or soluble thin-film techniques.

Until now, $\mathrm{ZnO}$ is still considered an ideal candidate for realizing new transparent and flexible electronics for flat panel display, such as transparent thin-film transistors (TTFTs). Compared with organic TFTs, these oxide TTFTs clearly have more potential for OLED since the mobility is higher and the soluble fabrication is less equivalent to a-Si and simple than LTPS process, which results in higher drive currents, low cost, resolution raising, and uniform largearea fabrication [5]. Zinc oxide films have been studied and fabricated as the active channel of TTFTs using vacuum or soluble processing, such as sputtering, pulsed laser deposition (PLD), chemical vapor deposition (CVD), atomic layer deposition (ALD), spin coating, spray, chemical bath deposition (CBD), and several printing techniques [1117]. An important advantage of $\mathrm{ZnO}$ is one oxide that can be crystallized at relatively low temperature, which indicates that the solution processes are introduced into the high-quality film production in place of lithographically defined deposition on plastic substrates for flexible displays. However, TFT devices based on polycrystalline $\mathrm{ZnO}$ as active layer by various processes have been reported with mobilities of about $0.2-3 \mathrm{~cm}^{2} / \mathrm{Vs}[18-21]$.

Recently, Inkjet printing (IJP) technology has been used as a low-cost research appliance in laboratory environment, depositing various experimental soluble materials of printing electronics as semiconductors, dielectrics, or conducting constructions of devices, such as the of OTFT, LED, solar cell, metalize, memory, and sensors [22]. IJP is part of noncontact, wide material applications and mask-free deposited technology. The advantage of directly printed property by IJP can achieve multilayer films with various functional inks in one device, simply process and rapidly revise print patterns via controlling digital design for patternable. Other 
attractive advantages of inkjet-printed electronic include low cost, reducing material waste, and fabrications of large area for roll to roll.

The aim of this work is to prepare and disperse $\mathrm{ZnO}$ NPs solutions in high boiling point solvent by dispersants for the inkjet-printed active layer of TFTs. The printed inks were prepared using Poly(4-vinylphenol) (PVP) and zinc acetate dehydrate, which were used for the gate dielectric and semiconductor films of TFTs as precursors, respectively. The thin films of TFTs were deposited on ITO/glass substrates by inkjet printing at low temperature.

\section{Experimental}

2.1. Preparations of the Semiconductor and the Dielectric Materials. In this work, two types of device were fabricated and shown in Figure 1. The polymer dielectric layers were formed in a metal-insulator-metal (MIM) structure and topcontact TFT device. The cross-linked PVP (Mw 25,000, from Aldrich) and cross-linking reagent poly(melamine-coformaldehyde) methylated (PMCF, Mw = 511, from Aldrich) dissolved uniformly in propylene glycol monomethyl ether acetate (PGMEA) were selected as the polymer matrix for the soluble dielectric.

According to a previous literature by Baoquan [23], $\mathrm{ZnO}$ nanoparticles (NPs) were synthesized by mixing a methanol solution (mol ratio, $\mathrm{KOH}: \mathrm{Zn}(\mathrm{Ac})_{2}=1.6: 1.0$ ), comprising $29.58 \mathrm{~mL}$ of $0.31 \mathrm{M}$ potassium hydroxide, $53.98 \mathrm{~mL}$ of $0.11 \mathrm{M}$ Zinc acetate, and $320 \mathrm{uL}$ of water, then heating and magnetic stirring at $60^{\circ} \mathrm{C}$ for $5 \mathrm{~h}$ to acquire an opaque suspension.

The transparent part of the staying solution was taken away after $30 \mathrm{~min}$ and $30 \mathrm{~mL}$ of methanol is readded into the solution then stirring for 5 min twice. The suspension after washings to $16.9 \mathrm{~mL}$ in the second washing then stands for $12 \mathrm{~h}$. To well control the solid concentration of $\mathrm{ZnO}$ in the suspension from 3.92 to $3.0 \mathrm{wt} \%$, we used $2.8 \mathrm{~mL}$ of the suspension to calculate the requirement of the solvent (methanol) and readded about $2.78 \mathrm{~g}$.

Finally, the suspension was mixed with $16.2 \mathrm{~mL}$ of PGMEA (V:V, 50:50), then $14 \mathrm{mg}$ of the polyester dispersant $(4.0 \%$ wt. for $\mathrm{ZnO}-\mathrm{NPs})$ and $0.26 \mathrm{~mL}$ of $n$-butylamine $(0.8 \%$ vol. $)$ were dissolved in the mixture to obtain a clear solution, which was used to disperse the $\mathrm{ZnO}$ nanoparticles. We utilize another higher boiling point solvent as the second matrix in order both to prevent the jetting nozzle from clogging and to inhibit convective flow in evaporation process. The NPs solid content of $\mathrm{ZnO}$ inks is 3 and $7 \mathrm{wt} \%$. To investigate the relation between characterizations of $\mathrm{ZnO}$ NPs film and the composite of suspensions, we prepare $\mathrm{ZnO}$ NPs suspensions and $\mathrm{ZnO}-\mathrm{NPs} / \mathrm{Zn}^{2+}$ mixture, which were possessed at the concentration of $3 \mathrm{wt} \%$.

2.2. Fabrication of Devices. Bottom-gate, top-contact TFTs were fabricated on a glass substrates and shown in Figure 1. $100 \mathrm{~nm}$ thick indium tin oxide (ITO) layer was thermally deposited as a gate electrode on the glass substrate. After cleaning the glass with acetone in an ultrasonic bath, the polymer solution as gate dielectrics on ITO glass substrates

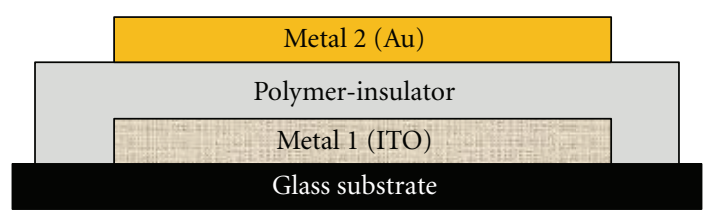

(a)

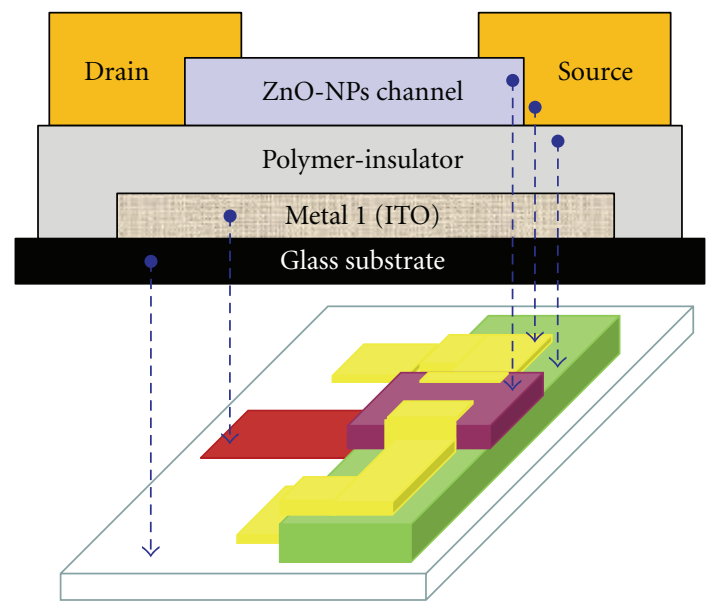

(b)

Figure 1: (a) Sandwich structure (MIM) of PVP gate dielectric insulator. (b) Configuration of "bottom-gate" and "top-contact" structure of a $\mathrm{ZnO}-\mathrm{NPs}$ TFT with the polymer gate dielectric.

was prepared by inkjet printing with a thickness of 1-2 um, from the filtered ( 0.45 um PTFE filter) compound slurry and then baked at $190^{\circ} \mathrm{C}$ for $30 \mathrm{~min}$. To obtain the leakage current density and dielectric constant, gold was thermally evaporated through the shadow mask and used as cover electrodes of the MIM structure.

To comparison, as the electrodes for Hall measurement, Mo was deposited onto the spin-cast films of $\mathrm{ZnO}-\mathrm{NPs}$ and $\mathrm{ZnO}-\mathrm{NPs} / \mathrm{Zn}^{2+}$ (S.C. $\left.=3 \mathrm{wt} \%\right)$ on PVP layer and postannealed at $200^{\circ} \mathrm{C}$ for $1 \mathrm{~h}$ in air ambient or reducing atmosphere (RA).

To fabricate top-contact TFT structure, $\mathrm{ZnO}-\mathrm{NPs}$ ( 3 and $7 \mathrm{wt} \%$ ) filtered through a $0.45 \mathrm{um}$ PTFE filter (Advantec MFS), is inkjet printed as an inorganic semiconductor layer on ITO/glass substrates with $1.2 \mathrm{um}$ thick PVP, and its thickness was about $2 \mathrm{um}$. The resulting films are dried at $180^{\circ} \mathrm{C}$ for $2 \mathrm{hr}$ to evaporate the solvent and annealed at $200^{\circ} \mathrm{C}$ for $1 \mathrm{~h}$ in reducing atmosphere for achieving thermal decomposition of organic residues, metal salts, and the carboxylate anion. Finally, the gold source/drain electrodes are thermally evaporated through the shadow mask on top of the ZnO-NPs layer on PVP/glass, which has the ratio of channel width $(W)$ and length $(L)$ are 2.

The printer constituted a drop-on-demand (DOD) piezoelectric inkjet nozzle (with a drop volume of $1-10 \mathrm{pL}$ ) produced by Dimatix (DMP-2800) is used in this work. The print head with 16 nozzles at $254 \mu \mathrm{m}$ spacing in single row is mounted onto a computer-controlled three-axis gantry system exhibiting a movement accuracy of \pm 25 um. Stably droplet ejecting is accomplished by applying an 11.5 us long 


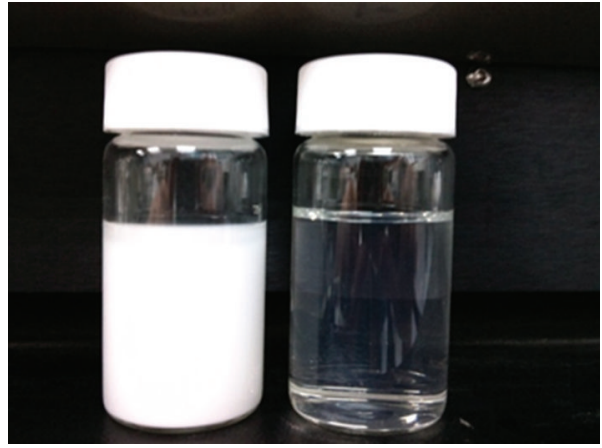

(a)

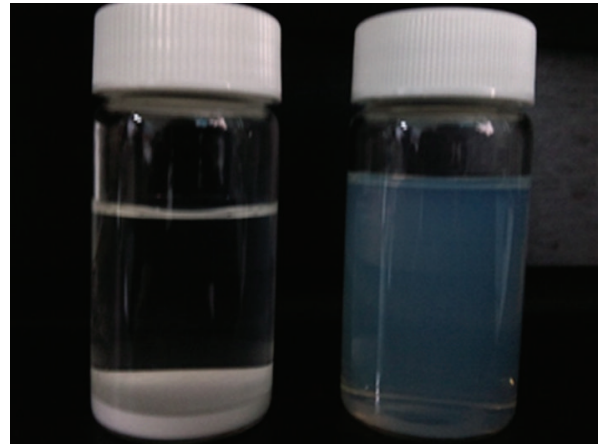

(b)

Figure 2: Transparency and sedimentation observation result of suspensions comprising the ZnO nanoparticles without dispersants and $\mathrm{ZnO}$ nanoparticles with dispersants after (a) $0 \mathrm{hr}$ and (b) 2 weeks.

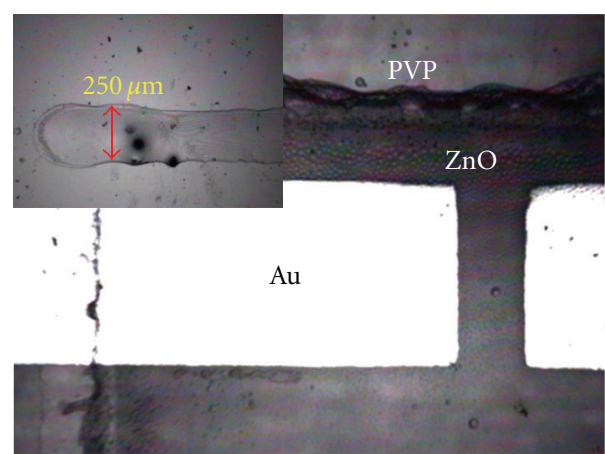

(a)

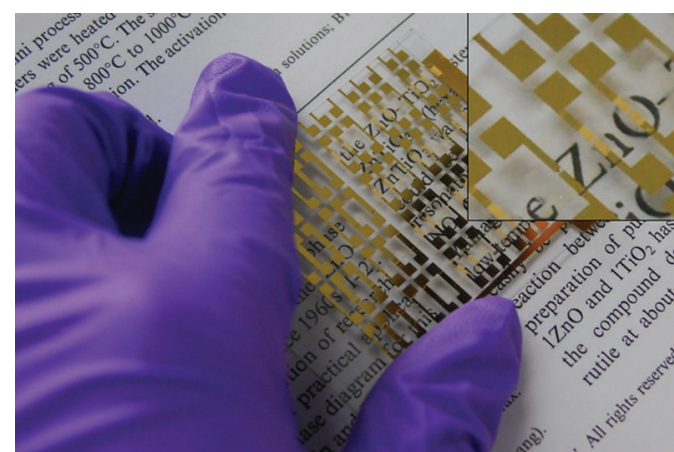

(b)

Figure 3: Photos of inkjet-printed patterns obtained from $\mathrm{ZnO}$ NPs ink (3 wt $\%$ ) as a function: (a) microscope images; (b) the devices on a glass substrate on one paper.

$17 \mathrm{~V}$ pulse at a frequency of $1 \mathrm{kHz}$. The drop spacing was regulated at about $5 \mathrm{um}$ during printing, and layer counts were 3 (and $20 \mathrm{~V}, 1 \mathrm{kHz}$, and $10 \mathrm{um}$ of drop spacing).

\subsection{Measurements. For spin coating and inkjet printing, a} vacuum sintering furnace, filled air, or reducing atmosphere was used to anneal the $\mathrm{ZnO}$ NPs film. The thicknesses of the films were measured by an Alpha-Step Profilometer. A Hall measurement was performed to characterize the carrier concentration and Hall mobility of spin-coated $\mathrm{ZnO}$ NPs films on PVP/glass substrates by annealing in various atmospheres. To obtain the optical absorption properties of inkjet-printed $\mathrm{ZnO}-\mathrm{NPs}$ films, the spectra were measured using a double beam UV-VIS-NIR spectrophotometer (Jasco $\mathrm{V}-670$ ). Phase transformation and crystallization were measured using high resolution X-ray diffraction (X PETPRO MRD, Phillips). The current-voltage $(I-V)$ characteristics of MIM were measured by an HP $4156 \mathrm{~A}$ semiconductor parameter analyzer. The capacitance measurements were conducted with an HP 4284A Precision LCR meter. All the measurements were carried out at room temperature in the dark. The surface microstructures of $\mathrm{ZnO}$ film on the dielectrics were characterized using a scanning electron microscope (SEM, XL-40FEG, Philips).

\section{Results and Discussion}

A sedimentation test was supplied by the $\mathrm{ZnO}-\mathrm{NPs}$ suspensions with the added amines of 0 and 5.2 -vol\%, whose result after $0 \mathrm{hr}$ and 2 weeks is presented in Figures 2(a) and 2(b), respectively. While the butylamine dissolve in the solution, the rapid changes to transparent and remains with addedbutylamine of $3 \mathrm{wt} \%$. It was observed that the suspension without butylamine have been precipitated obviously and the ink sample containing the amines remains stable.

3.1. Morphological Properties. Figures 3 and 4 show the optical microscope and scanning electron micrograph of the $\mathrm{ZnO}$ thin film on a PVP/ITO/glass substrate, respectively. It was observed that hexagonal particles were closely packed on the substrate. The hexagonal particles seem to grow from the surface of the substrate. The pole formation may occurr due to the rapid evaporation rate of the solvent by the low boiling temperature or the viscosity excessively low to aggregate the ZnO NPs film with possibly high fluidity. In organic slurry, in order to disperse uniformly nanoparticles, the smaller molecular and shorter chain dispersants such as amines, phosphate esters, fatty acids, or carboxyl acids are used [23, 24]. In certain literature, increasing solid 


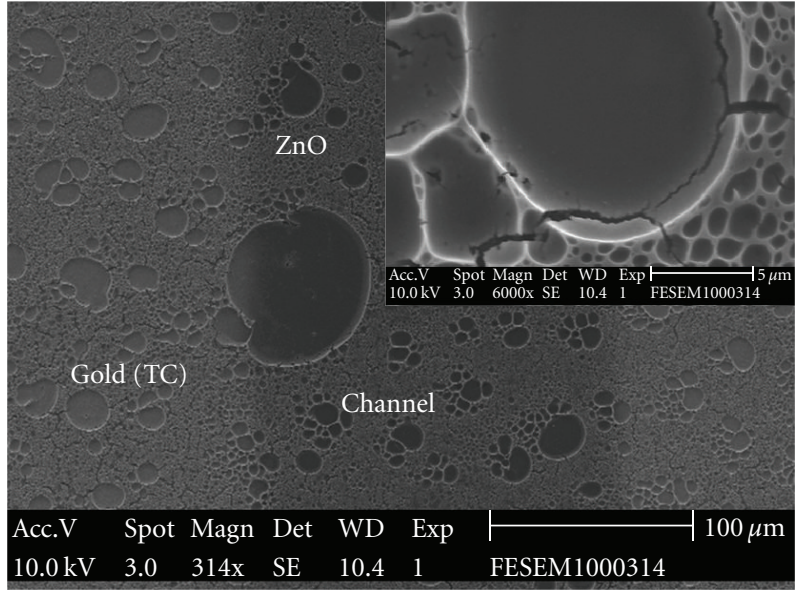

(a)

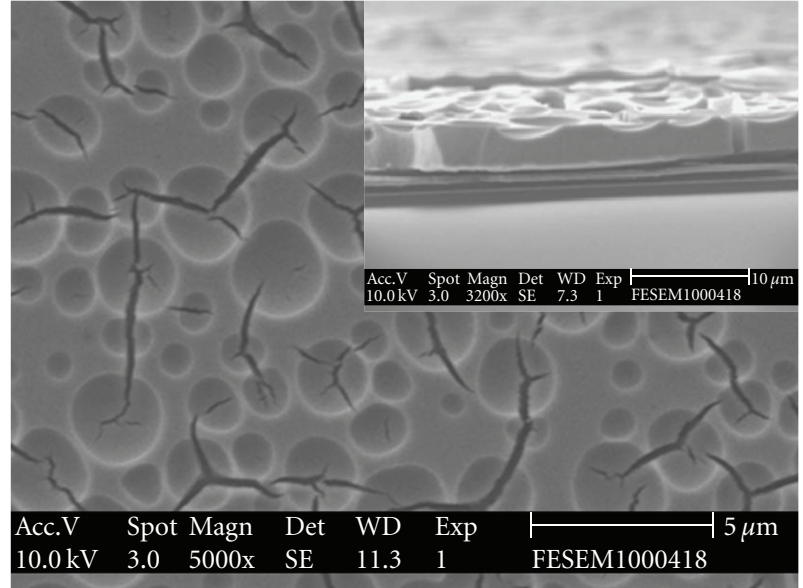

(b)

FIGURE 4: Scanning electron microscopy image of the inkjet-printed ZnO-NPs film using various concentrations onto the IJP-dielectric layer of a top-cntact transistor (plain view): (a) $3 \mathrm{wt} \%$; (b) $7 \mathrm{wt} \%$.

phase in the coating solution could decrease the shrinkage and pole for growth of smooth films [25]. Nevertheless, we obtained the different result and Figure 5 illustrated dispersants with lower boiling point such as butylamine in Marangoni flow mechanism [26]. Butylamine [23] as a ligand with a shorter chain and a low boiling point $\left(78^{\circ} \mathrm{C}\right)$ can instead of the comprise acetate $\left(\mathrm{CH} 3 \mathrm{COO}^{-}\right)$ligand groups chelating with zinc atoms on the surface of $\mathrm{ZnO}$ nanocrystals to help achieve high-concentration dispersions of the suspension, hence the residual groups can be removed readily. In particular, butylamine in the higher solid phase content of the $\mathrm{ZnO}-\mathrm{NPs}$ suspension evaporated faster than other solvent to the nanoparticles aggregated due to the high surface energy during drying, which may results in crack, split and unsmooth by non-uniform deposition and stress after annealing.

3.2. Structural Properties. The properties of the $\mathrm{ZnO}$ thin films fabricated by inkjet-printing under the appropriate conditions are examined. Figures $6(\mathrm{a})-6(\mathrm{~d})$ show the X-ray diffraction spectrum of the $\mathrm{ZnO}$ nanoparticle powder, spincast film, and inkjet-printed film. In Figure 6(a) of X-ray diffraction spectrum, the peaks at $2 \theta=31.72,34.36,36.18$, 47.44 , and $56.5^{\circ}$, corresponding to the lattice planes (100), (002), (101), (102), and (110), respectively, of the hexagonal phase of $\mathrm{ZnO}$ [27], were present. The XRD pattern indicates that the longer heating condensation time could enhance the orientation of (101) phase, which anticipate enhancing the crystallinity of the $\mathrm{ZnO}-\mathrm{NPs}$ layer for the performance of these devices. The peak at $2 \theta=36.04^{\circ}$, which corresponds to the diffraction from the (101) plane, and the stronger crystalline quality were attributed to $\mathrm{Zn}^{2+}$ in the mixture as shown in Figures 6(b) and 6(c). The patterns also exhibited that the spin-cast $\mathrm{ZnO} / \mathrm{Zn}^{2+}$ film formed on PVP dielectric by annealing in RA at low temperature of $200^{\circ} \mathrm{C}$ had polycrystalline property in evident, which probably scatters or trap the carriers of transport.

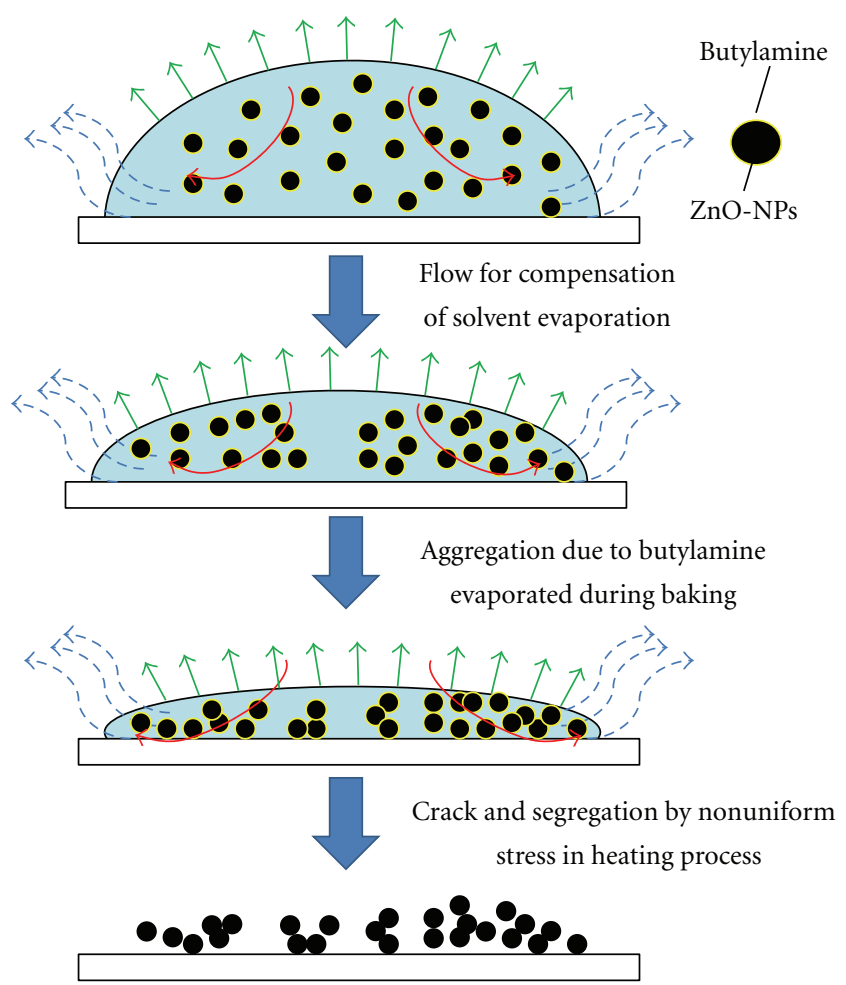

FIGURE 5: The modified formation process of droplet drying onto the surface of the substrate with inkjet printing [26].

The crystallite size of $\mathrm{ZnO}$ nanoparticles with increase in synthesis time was calculated using Scherrer's formula from Cullity (1970):

$$
D=\frac{0.9 \lambda}{B \cos \theta}
$$

where $\lambda, \theta$, and $B$ are the X-ray wavelength $(1.54056 \AA)$, Bragg's angle, and the full width at half maximum (FWHM) 


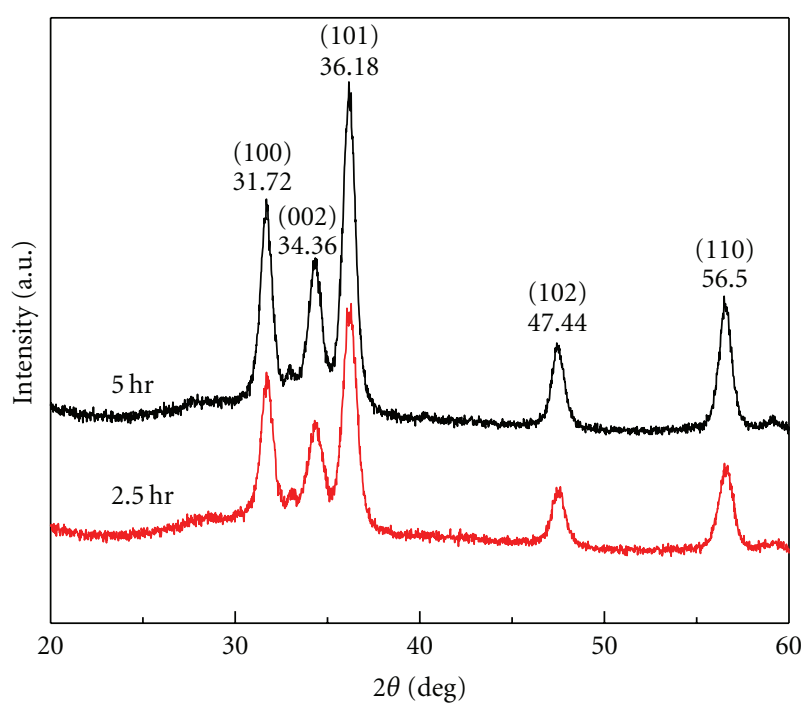

- ZnONPs50

(a)

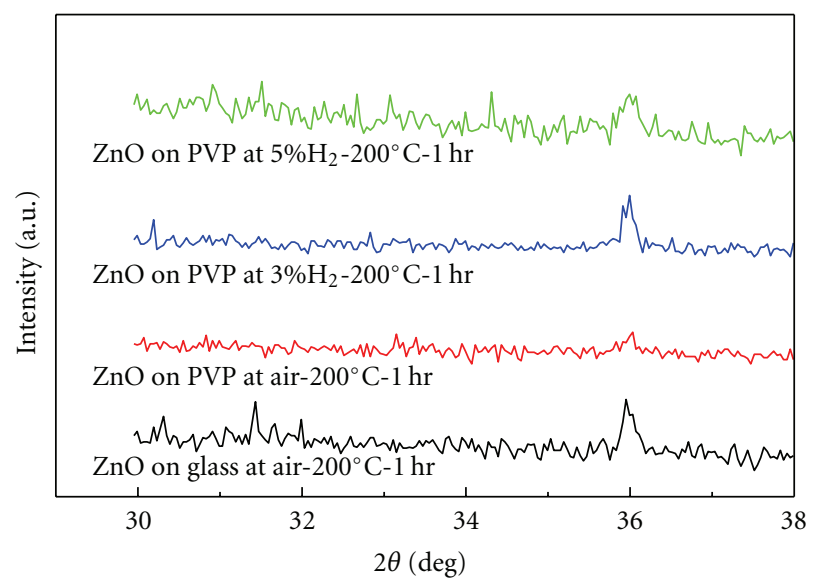

(b)

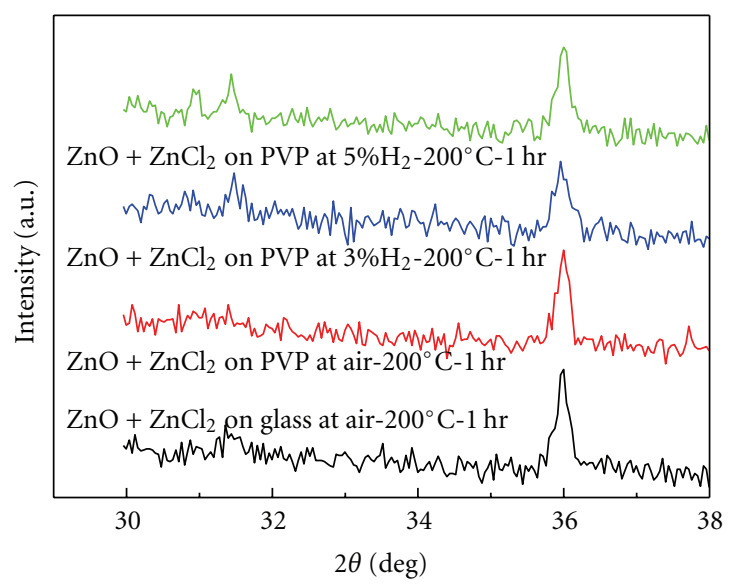

(c)

FIGURE 6: XRD patterns of $\mathrm{ZnO}$ with different composite of inks after annealing in various atmospheres: (a) nanoparticles of different synthesis times; (b) and (c) spin-cast films with inks of $\mathrm{ZnO}-\mathrm{NPs}$ and $\mathrm{ZnO}-\mathrm{NPs} / \mathrm{Zn}^{2+}$, respectively.

of the peak. It was found that the average sizes of $\mathrm{ZnO}$ particles in 2.5 and $5.0 \mathrm{hr}$ are 9.7 and $13.06 \mathrm{~nm}$, respectively. The sizes of crystallites corresponding to major diffracting plan are summarized in Table 1. We remark that the crystallites are smaller on the surface of the PVP film, except $\mathrm{ZnO}-\mathrm{NPs}$ annealed in RA (3vol\%), which demonstrates the lager grain size with decreasing the amount of grain boundary.

3.3. Optical Properties. Figure 7 shows the optical transmittance spectrum of the entire IJP-ZnO film (excluding other layers of device or substrate), which exhibits the energy gap of $\sim 3.35 \mathrm{eV}$. The transmittance pattern in visible part of the spectrum $(400-700 \mathrm{~nm})$ is around $60-70 \%$, while the printed film with the lower concentration of the suspension.
3.4. Electrical Properties. The current density-voltage characteristic of inkjet-printed PVP dielectric is shown in Figure 8. The insets in Figure 8 show an optical image and profiler measurement result of the inkjet-printed PVP layer. We obtained that the IJP film possesses a leakage current less than $10^{-8} \mathrm{~A} / \mathrm{cm}^{2}$ under bias of $100 \mathrm{~V}$ applied. Nevertheless, taking into account the insulator thickness excluding the gate contact, the dielectric strength of the IJP-film was calculated about $0.83 \mathrm{MV} / \mathrm{cm}$. The stronger strength with thick layer can resist the device work, but induced carriers in the active channel of a transistor in "on" mode decreas due to the weak polarity. We also calculated the dielectric constant of 4.17 at $1 \mathrm{kHz}$ by the $\mathrm{C}-\mathrm{V}$ characteristic analyzed.

The ZnO-NPs deposited on glass and PVP/glass by annealing at low temperature of $200^{\circ} \mathrm{C}$ and exhibited Hall effect mobilities of the latter samples in RA exceeding 
TABLE 1: Crystallite sizes calculated from XRD.

\begin{tabular}{|c|c|c|c|c|}
\hline Composite & $\begin{array}{l}\text { Substrate, } \\
\text { atmosphere } \\
\text { condition }\end{array}$ & $2 \theta\left(^{\circ}\right)$ & $\begin{array}{l}\text { FWHM } \\
\text { (rad) }\end{array}$ & $\begin{array}{c}D \\
(\mathrm{~nm})\end{array}$ \\
\hline \multirow{4}{*}{$\begin{array}{l}\mathrm{ZnO}-\mathrm{NPs} \\
(\mathrm{S} . \mathrm{C} .=3 \mathrm{wt} \%)\end{array}$} & Glass & 36 & $3.5 \mathrm{E}-3$ & 41.8 \\
\hline & $\begin{array}{l}\text { PVP/glass, air } \\
\text { ambient }\end{array}$ & 36.08 & $3.5 \mathrm{E}-3$ & 41.8 \\
\hline & $\begin{array}{c}\mathrm{PVP} / \text { glass, } \mathrm{N}_{2}+ \\
\mathrm{H}_{2}-(3 \text { vol } \%)\end{array}$ & 36.04 & $2.6 \mathrm{E}-3$ & 55.7 \\
\hline & $\begin{array}{c}\mathrm{PVP} / \text { glass, } \mathrm{N}_{2}+ \\
\mathrm{H}_{2}-(5 \mathrm{vol} \%)\end{array}$ & 36.04 & $4.5 \mathrm{E}-3$ & 32.1 \\
\hline \multirow{4}{*}{$\begin{array}{l}\mathrm{ZnO}-\mathrm{NPs}+\mathrm{Zn}^{2+} \\
(\text { S.C. }=3 \mathrm{wt} \%)\end{array}$} & Glass & 36.01 & $3.8 \mathrm{E}-3$ & 49.1 \\
\hline & $\begin{array}{l}\text { PVP/glass, air } \\
\text { ambient }\end{array}$ & 36.08 & $3.1 \mathrm{E}-3$ & 39.7 \\
\hline & $\begin{array}{c}\mathrm{PVP} / \text { glass, } \mathrm{N}_{2}+ \\
\mathrm{H}_{2}-(3 \text { vol } \%)\end{array}$ & 36.04 & $1.5 \mathrm{E}-2$ & 36.3 \\
\hline & $\begin{array}{c}\mathrm{PVP} / \text { glass, } \mathrm{N}_{2}+ \\
\mathrm{H}_{2}-(5 \text { vol } \%)\end{array}$ & 36.04 & $6.2 \mathrm{E}-3$ & 23.2 \\
\hline
\end{tabular}

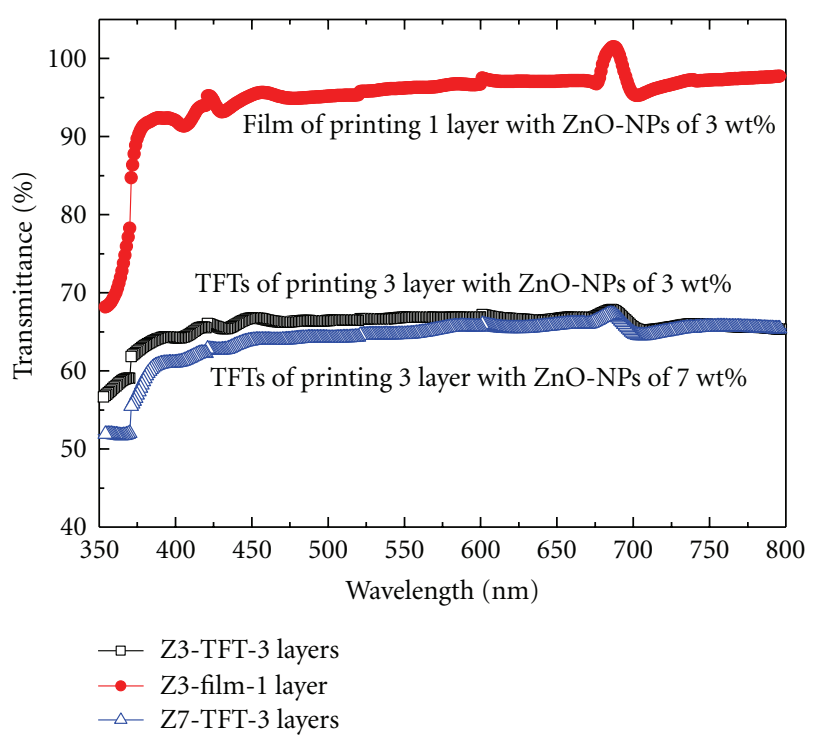

FIgURE 7: Plots of the measured optical transmission spectrum of the 1 layer $\mathrm{ZnO}-\mathrm{NPs}$ of $3 \mathrm{wt} \%$ as a film; the device with 3 layer printed $\mathrm{ZnO}-\mathrm{NPs}$ of $3 \mathrm{wt} \%$ and $7 \mathrm{wt} \%$.

$8 \mathrm{~cm}^{2} / \mathrm{Vs}$ are shown in Figures 9(a) and 9(b), which have electric potential indeed with an order of magnitude larger than those of amorphous silicon for flexible electronics. A postannealing step at $200^{\circ} \mathrm{C}$ in an $\mathrm{H}_{2}+\mathrm{N}_{2}$ (3 vol\%) atmosphere was performed to improve the electrical performance of the other transistors for the measurement.

Finally, we implemented successfully the printer using a well-dispersed $\mathrm{ZnO}-\mathrm{NPs}$ suspension to fabricate the active layer and gate dielectric of a top-contact TFT (TC-TFT) at low temperature. Figure 10 shows the transfer and output characteristic of $\mathrm{ZnO}$-NPs-based TFTs fabricated using inkjet-printed active channel and gate dielectric. The $I_{\mathrm{D}^{-}}$ $V_{\mathrm{D}}$ curve of the $\mathrm{ZnO}$-based TFT device was measured for the output drain current as the drain voltage $\left(V_{\mathrm{D}}\right)$

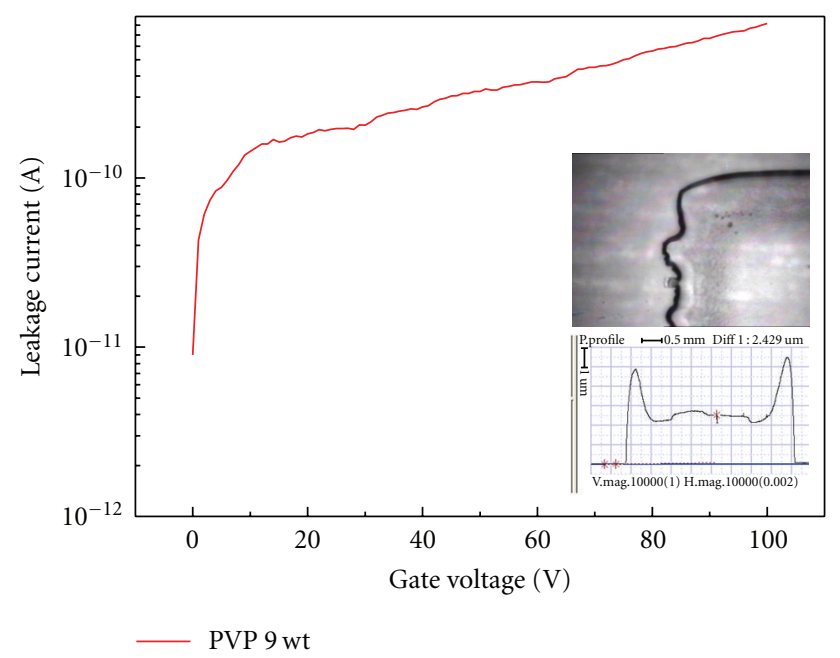

FIGURE 8: Leakage current density-voltage characteristic of the inkjet-printed gate dielectric layer. Optical microscopy image and thickness measurement of the inkjet-printed dielectric layer on ITO/glass (plain view).

was swept from $0-60 \mathrm{~V}$ at gate voltage of $0-50 \mathrm{~V}$ in $10 \mathrm{~V}$ increments. The $I_{\mathrm{D}}-V_{\mathrm{D}} \mathrm{ZnO}$-based TC-TFT shows a typical electrical behavior, pinch-off, and current saturation. It also was observed that the device turns off with zero gate bias indicating that the $\mathrm{ZnO}$-NPs TFT operate in accumulation mode. The field effect mobility $(\mu)$ is calculated from the saturation regime of the transfer characteristics with the the following relationship for the continuous thin film [28]:

$$
\mu=\frac{L \cdot g_{m}}{W \cdot C_{\mathrm{ox}} \cdot V_{\mathrm{DS}}},
$$

where $L, W$, and $C_{\mathrm{ox}}$ indicate the channel length, channel width, and dielectric capacitance, respectively. The offcurrent, current on/off ratio, saturation field mobility, and threshold voltage calculated are $1.2 \times 10^{-8} \mathrm{~A}, \sim 4 \times 10^{1}$ $0.69 \mathrm{~cm}^{2} / \mathrm{Vs}$, and $25.5 \mathrm{~V}$, respectively. The ZnO-NPs-based TC-TFT has identical saturation field mobility and offcurrent. However, the mobility is still lower than those published $\mathrm{ZnO}$-TFTs. The on-current did not rise effectively may be attributing to the $\mathrm{ZnO}-\mathrm{NPs}$ film quality, poor polarity by thick PVP, or interface characteristics of heterolayers. Raising the sheet resistance and excess defect formation due to the rapider evaporation of butylamine in the suspension from the film surface result in adjacent NPs as-aggregated each during the drying process, which made the on-current decline. In Figure 4, we observed films printed with lowconcentration suspension reducing the defect such as crack and split. Nevertheless, the inkjet-printed ZnO-NPs-based TFT device is suitable for flat plate display, which would be applied further.

\section{Conclusions}

In conclusion, we have made good use of sol-gel method to prepare $\mathrm{ZnO}$ NPs ink, introduce soluble polymer, and 


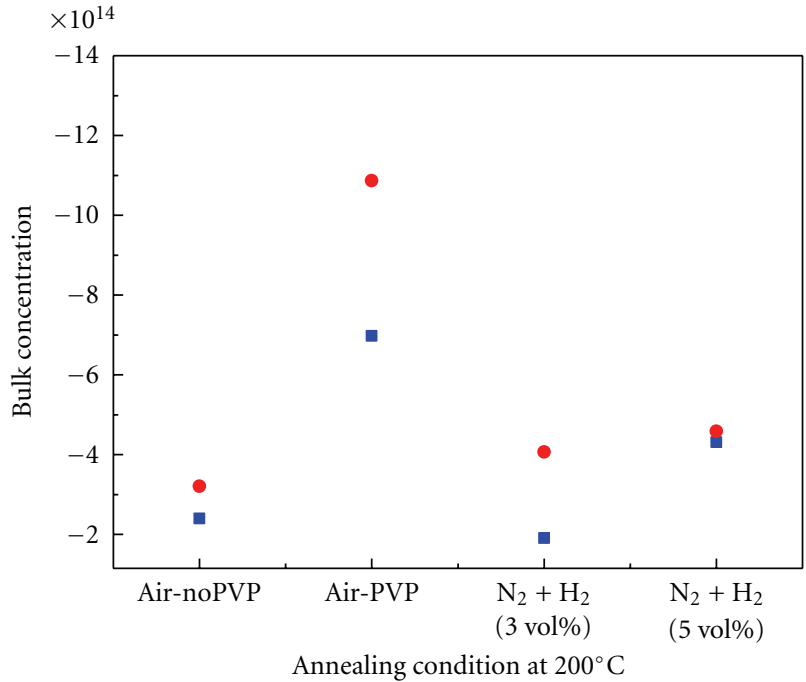

- $\mathrm{Nb}-\mathrm{ZnO}$

- $\mathrm{Nb}-\mathrm{ZnO}+\mathrm{Zn}$ ion

(a)

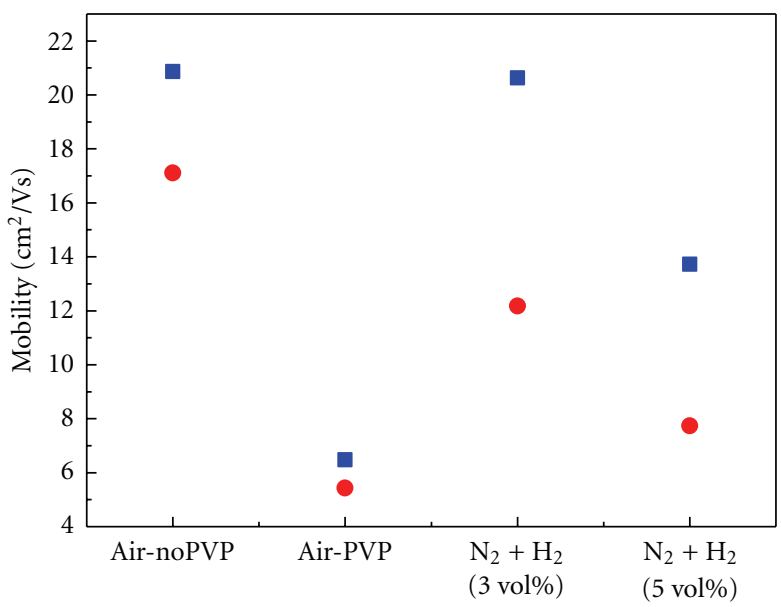

Annealing condition at $200^{\circ} \mathrm{C}$

Mobility-ZnO

- Mobility-ZnO + Zn ion

(b)

FIgure 9: (a) Bulk concentrations and (b) Hall mobilities of the spin-cast $\mathrm{ZnO}-\mathrm{NPs}$ and $\mathrm{ZnO}-\mathrm{NPs} / \mathrm{Zn}^{2+}$ films on gate dielectric.

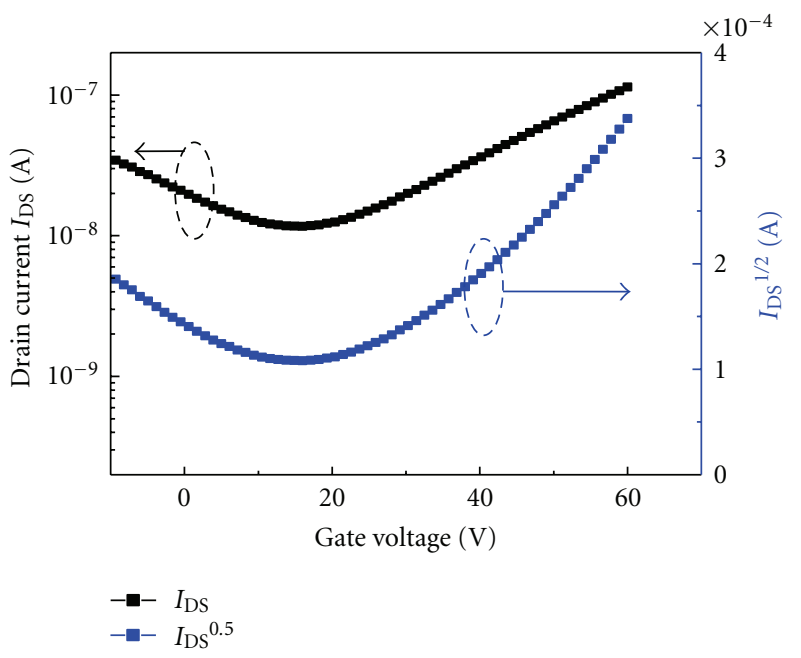

(a)

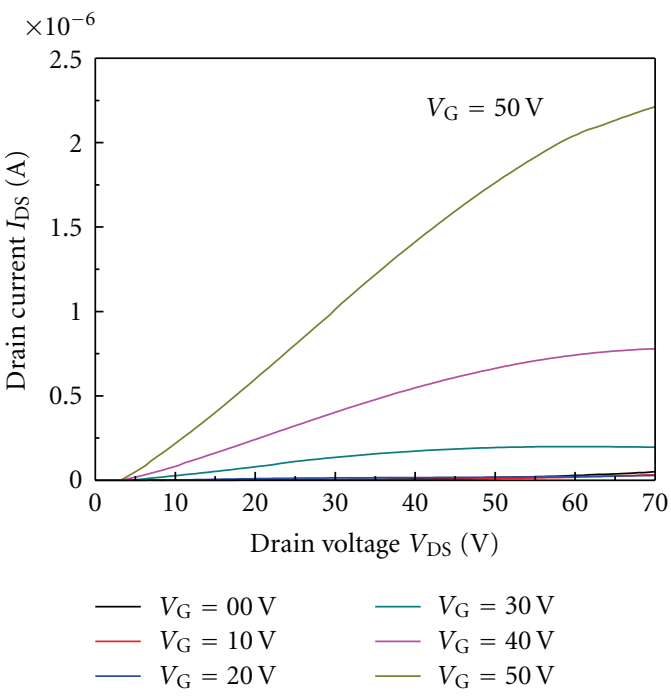

(b)

FIGURE 10: Transfer and output characteristic of ZnO-based TFTs fabricated using inkjet-printed active channel and gate dielectric layers.

fabricated directly printable gate dielectric films and active channel layers for TFTs using inkjet printing. For printing with mask-free process of semiconductor, preparing the $\mathrm{NP}$ inks by dispersant and butylamine, the nano- $\mathrm{ZnO}$ particles in the suspension were well dispersed to transparent and more stable effectively for more than 2 weeks then micronozzle jets successfully. Furthermore, in this work, we successfully utilize inkjet printing process to fabricate the active and insulator layers of TFT devices. It is expected that it is possible to implement the low-cost nanoparticles materials and high-performance devices using a simple solution-based fabrication processes.

\section{Acknowledgments}

This work was supported by the National Science Council (NSC), Taiwan, under Contract no. NSC99-2221-E-006089. 


\section{References}

[1] M. Abbas, G. Cakmak, N. Tekin et al., "Water soluble poly(1vinyl-1,2,4-triazole) as novel dielectric layer for organic field effect transistors," Organic Electronics, vol. 12, no. 3, pp. 497503, 2011.

[2] K. -J. Baeg, D. Khim, J. -H. Kim et al., "Improved performance uniformity of inkjet printed n-channel organic field-effect transistors and complementary inverters," Organic Electronics, vol. 12, no. 4, pp. 634-640, 2011.

[3] G. Generali, R. Capelli, S. Toffanin, A. Facchetti, and M. Muccini, "Ambipolar field-effect transistor based on $\alpha, \omega$ dihexylquaterthiophene and $\alpha, \omega$-diperfluoroquaterthiophene vertical heterojunction," Microelectronics Reliability, vol. 50, no. 9-11, pp. 1861-1865, 2010.

[4] J. Robertson, "Disorder, band offsets and dopability of transparent conducting oxides," Thin Solid Films, vol. 516, no. 7, pp. 1419-1425, 2008.

[5] R. A. Street, "Thin-film transistors," Advanced Materials, vol. 21, no. 20, pp. 2007-2022, 2009.

[6] J. H. Ko, I. H. Kim, D. Kim et al., "Effects of $\mathrm{ZnO}$ addition on electrical and structural properties of amorphous $\mathrm{SnO}_{2}$ thin films," Thin Solid Films, vol. 494, no. 1-2, pp. 42-46, 2006.

[7] D. Kim, Y. Jeong, K. Song, S. K. Park, G. Cao, and J. Moon, "Inkjet-printed zinc tin oxide thin-film transistor," Langmuir, vol. 25, no. 18, pp. 11149-11154, 2009.

[8] S. Dutta and A. Dodabalapur, "Zinc tin oxide thin film transistor sensor," Sensors and Actuators, B: Chemical, vol. 143, no. 1, pp. 50-55, 2009.

[9] D.-H. Lee, Y.-J. Chang, G. S. Herman, and C.-H. Chang, "A general route to printable high-mobility transparent amorphous oxide semiconductors," Advanced Materials, vol. 19, no. 6, pp. 843-847, 2007.

[10] H. Hosono, "Ionic amorphous oxide semiconductors: Material design, carrier transport, and device application," Journal of Non-Crystalline Solids, vol. 352, no. 9-20, pp. 851-858, 2006.

[11] T. Yoshida, T. Tachibana, T. Maemoto, S. Sasa, and M. Inoue, "Pulsed laser deposition of $\mathrm{ZnO}$ grown on glass substrates for realizing high-performance thin-film transistors," Applied Physics A: Materials Science and Processing, vol. 101, no. 4, pp. 685-688, 2010.

[12] K. Haga, M. Sakuma, Y. Takizawa, and S. Seki, "Characteristics of $\mathrm{ZnO}$ thin film transistor prepared by two different methods," Physica Status Solidi C, vol. 7, no. 6, pp. 1715-1717, 2010.

[13] H. Kim, S. J. Lim, J. M. Kim, and D. Y. Kim, "High performance transparent thin film transistor with atomic layer deposition $\mathrm{ZnO}$ based active channel layer," in Oxide-based Materials and Devices, vol. 7603, 760310 of Proceedings of SPIE, San Francisco, Calif, USA, January 2010.

[14] C. S. Li, Y. N. Li, Y. L. Wu, B. S. Ong, and R. O. Loutfy, "Performance improvement for solution-processed high-mobility ZnO thin-film transistors," Journal of Physics D: Applied Physics, vol. 41, no. 12, 2008.

[15] G. Adamopoulos, A. Bashir, W. P. Gillin et al., "Structural and electrical characterization of $\mathrm{ZnO}$ films grown by spray pyrolysis and their application in thin-film transistors," Advanced Functional Materials, vol. 21, no. 3, pp. 525-531, 2011.

[16] H. C. Cheng, C. F. Chen, and C. Y. Tsay, "Transparent ZnO thin film transistor fabricated by sol-gel and chemical bath deposition combination method," Applied Physics Letters, vol. 90, no. 1, Article ID 012113, 2007.

[17] W. Lei, X. Zhang, Z. Zhao, and B. Wang, "A screen-printing triode with low driving voltage," in Proceedings of the Technical
Digest of the International Vacuum Nanoelectronics Conference (IVNC '09), pp. 33-34, Shizuoka, Japan, July 2009.

[18] P. F. Carcia, R. S. McLean, M. H. Reilly, and G. Nunes, “Transparent $\mathrm{ZnO}$ thin-film transistor fabricated by rf magnetron sputtering," Applied Physics Letters, vol. 82, no. 7, pp. 1117$1119,2003$.

[19] R. L. Hoffman, B. J. Norris, and J. F. Wager, "ZnO-based transparent thin-film transistors," Applied Physics Letters, vol. 82, no. 5, pp. 733-735, 2003.

[20] Y. Ohya, T. Niwa, T. Ban, and Y. Takahashi, "Thin film transistor of $\mathrm{ZnO}$ fabricated by chemical solution deposition," Japanese Journal of Applied Physics Part 1, vol. 40, no. 1, pp. 297-298, 2001.

[21] B. J. Norris, J. Anderson, J. F. Wager, and D. A. Keszler, "Spincoated zinc oxide transparent transistors," Journal of Physics D: Applied Physics, vol. 36, no. 20, pp. L105-L107, 2003.

[22] M. Singh, H. M. Haverinen, P. Dhagat, and G. E. Jabbour, "Inkjet printing-process and its applications," Advanced Materials, vol. 22, no. 6, pp. 673-685, 2010.

[23] B. Sun and H. Sirringhaus, "Solution-processed zinc oxide field-effect transistors based on self-assembly of colloidal nanorods," Nano Letters, vol. 5, no. 12, pp. 2408-2413, 2005.

[24] T. Chartier, E. Streicher, and P. Boch, "Phosphate esters as dispersants for the tape casting of alumina," American Ceramic Society Bulletin, vol. 66, no. 11, pp. 1653-1655, 1987.

[25] V. Abramova and A. Sinitskii, "Large-scale $\mathrm{ZnO}$ inverse opal films fabricated by a sol-gel technique," Superlattices and Microstructures, vol. 45, no. 6, pp. 624-629, 2009.

[26] J. A. Lim, W. H. Lee, H. S. Lee, J. H. Lee, Y. D. Park, and K. Cho, "Self-organization of ink-jet-printed triisopropylsilylethynyl pentacene via evaporation-induced flows in a drying droplet," Advanced Functional Materials, vol. 18, no. 2, pp. 229-234, 2008.

[27] G. Xiong, G. A. C. Jones, R. Rungsawang, and D. Anderson, "Non-aqueous solution processed $\mathrm{ZnO}$ thin film transistors," Thin Solid Films, vol. 518, no. 14, pp. 4019-4023, 2010.

[28] H. Pan, N. Misra, S. H. Ko et al., "Melt-mediated coalescence of solution-deposited $\mathrm{ZnO}$ nanoparticles by excimer laser annealing for thin-film transistor fabrication," Applied Physics A: Materials Science and Processing, vol. 94, no. 1, pp. 111-115, 2009. 

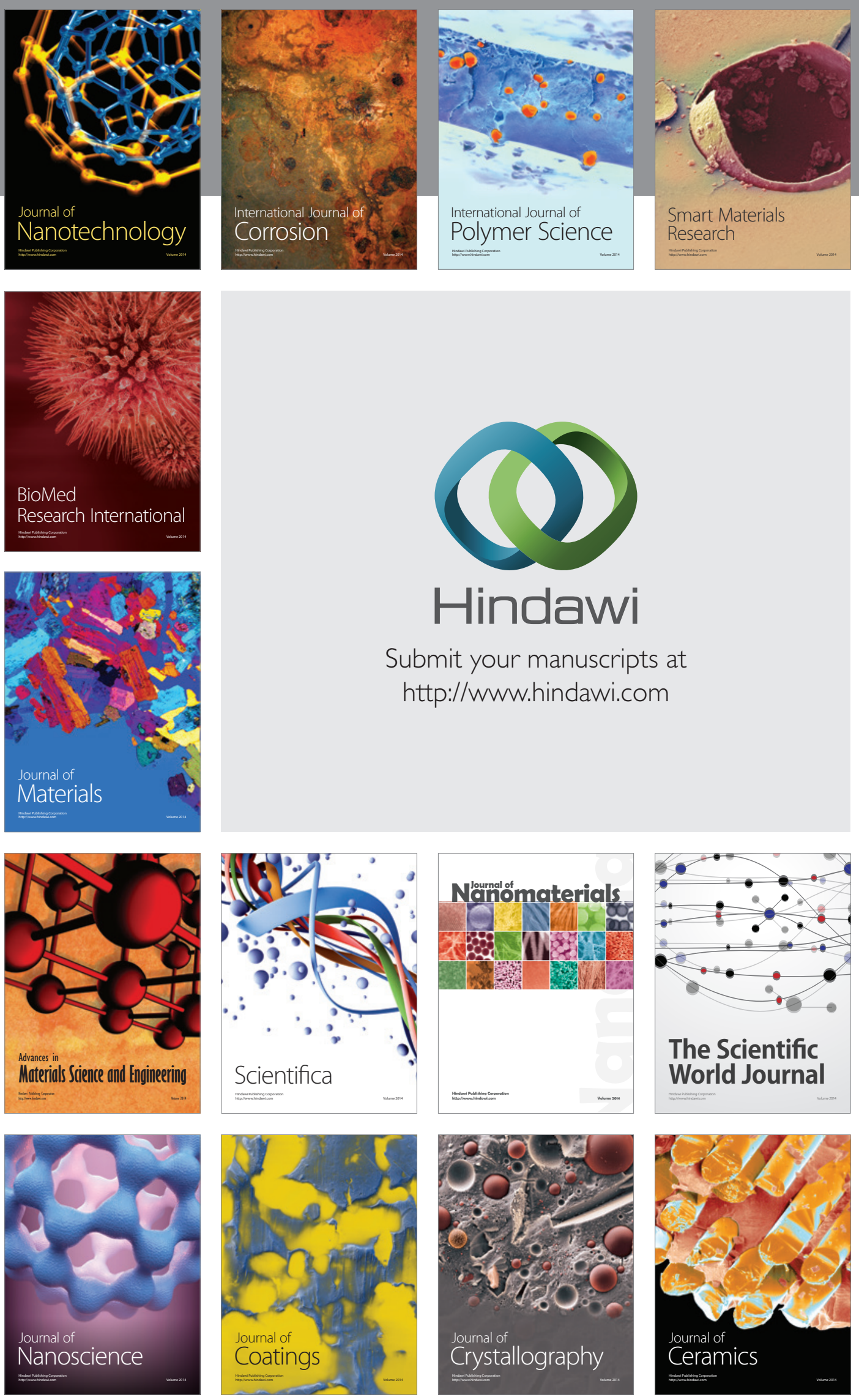

The Scientific World Journal

Submit your manuscripts at

http://www.hindawi.com

\section{World Journal}

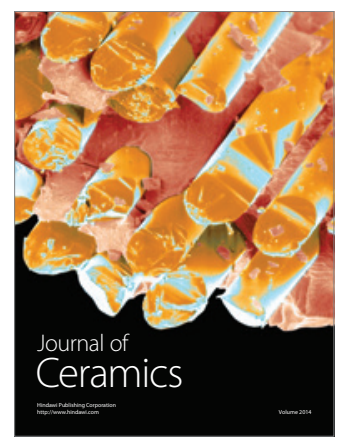

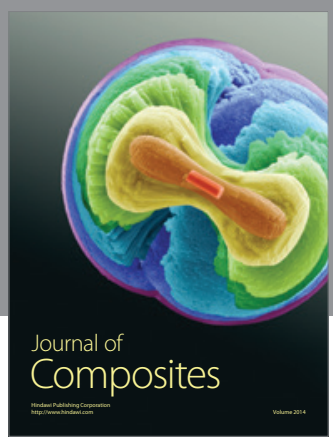
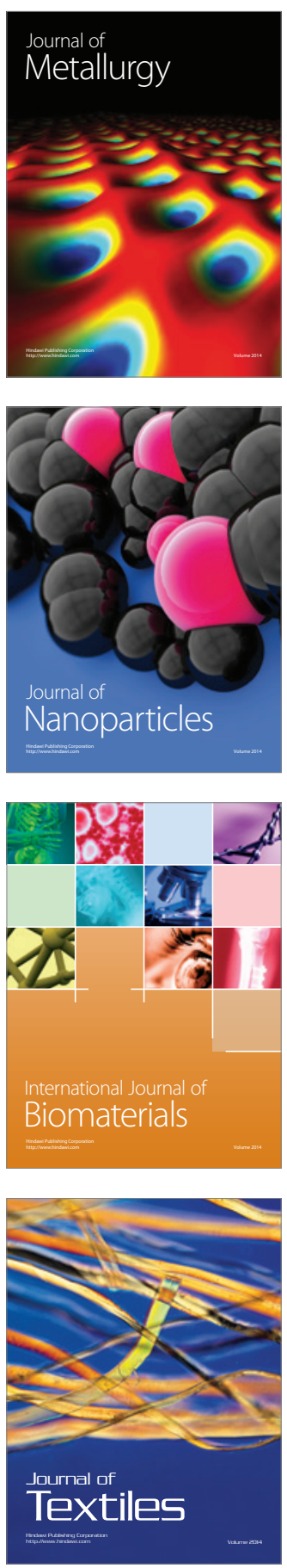